Thorax (1965), 20, 114.

\title{
Cardiac failure in malignant disease
}

\author{
J . J . T A Y L O R
}

From The General Hospital, Birmingham

Cardiac failure attributable to malignant disease is generally accepted as being caused either by lymphangitis carcinomatosa or by impaction of tumour emboli in the pulmonary vascular bed. Standard textbooks (Wood, 1956; Anderson, 1961) make no mention of other cardiac lesions which may occur in malignancy and which may be responsible for the development of heart failure. There are some less well-known causes of cardiac failure in malignant disease, and here I report five such cases and refer briefly to some problems of pathogenesis and management.

\section{CASE 1}

A 68-year-old woman, who had had acute rheumatism as a child but no subsequent disability, had an anterior resection of a well-differentiated adenocarcinoma from the pelvic colon. Five years later she began to develop cough, sputum, and progressive dyspnoea. Ten years after the operation she was admitted to this hospital with fever, foetid sputum, and congestive heart failure. A bedside diagnosis of subacute cor pulmonale due to infected cavitating metastatic carcinoma was made. Her haemoglobin was $70 \%$, E.S.R. (Westergren) $80 \mathrm{~mm}$. in the first hour, and her chest radiograph showed some enlargement of the pulmonary outflow tract and three large circumscribed shadows, that in the left upper lung field showing a fluid level (Fig. 1). No pathogenic bacteria or fungi were cultured. An electrocardiogram showed severe right heart strain (Fig. 2).

Temporary improvement for a week followed standard treatment for heart failure and chest infection, but then steady deterioration led to death three weeks after admission.

Necropsy showed no evidence of a new primary growth and no abdominal abnormality was noted. There was no evidence of recent or old cardiac infarction, and no stigmata of rheumatic disease were seen. The right ventricle was hypertrophied and dilated. Histologically the pulmonary metastases consisted of adenocarcinomatous tissue consistent with a colonic origin. There was much interstitial fibrosis in those parts of the tumour masses that were not

1 Present address : Haematology Department, Queen Elizabeth Hospital, Birmingham 15 necrotic, blood vessels being scanty. The pulmonar tissue elsewhere showed no malignant involvement.

\section{CASE 2}

A 77-year-old woman was admitted in congestive heart failure and with right-sided pleurisy five weeks after a simple mastectomy which had been performed. elsewhere. There was no previous history of lung disease nor clinical evidence of leg vein involvemenश A chest film showed similar appearances to that of case 1 with the presence of four large shadows but ne fluid levels. In addition to treatment for heart failure and lung infection, steroids and stilboestrol were use ${ }^{\$,}$, but she collapsed and died the following day.

At necropsy a large coiled pulmonary embolus obs structed the main branches of the pulmonary artery Its source was not evident and it did not contaio tumour tissue. In addition to the general congestiof there were four large pulmonary metastases wit? necrotic centres, though no local involvement of th $\overrightarrow{\vec{s}}$ chest wall or pleura was found.

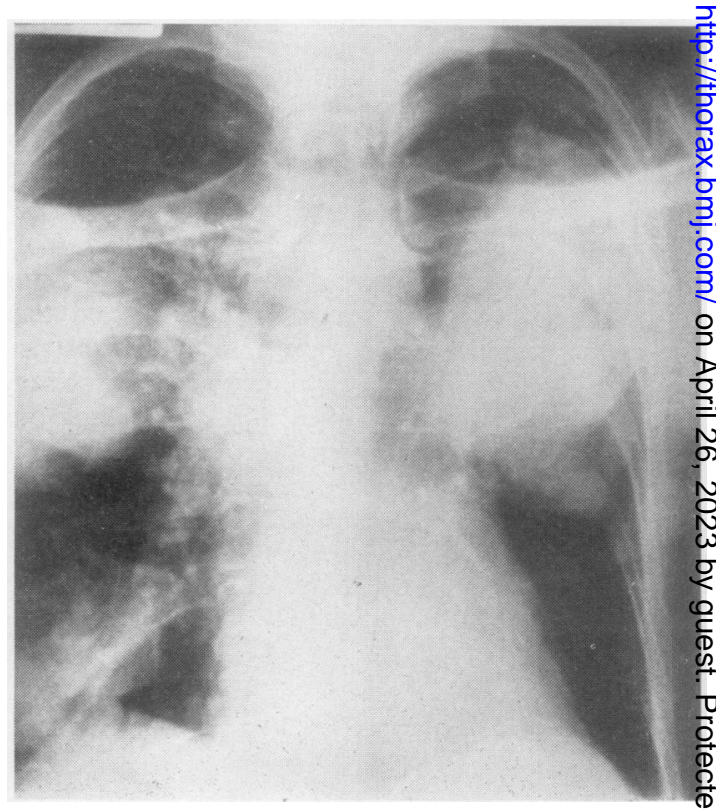

FIG. 1. Case 1. Postero-anterior skiagram showing fluig levels in three metastases. 
FIG. 2. Case 1. E.C.G. showing severe right heart strain.

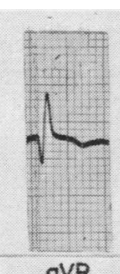

OVR

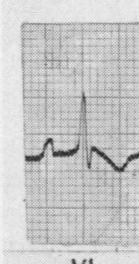

VI

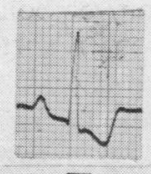

II

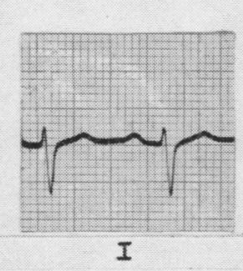

$I$

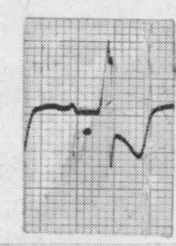

V2

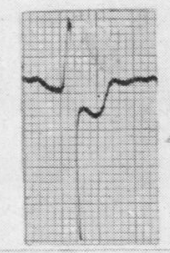

V/4

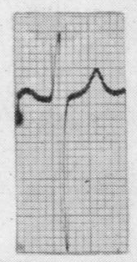

v5

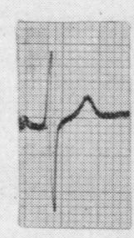

V6

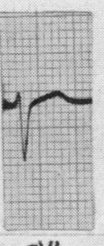

aVL
A 70-year-old woman presented with a nine years' history of shortness of breath and six years' ankle swelling. Angina pectoris had been present for four years but was rather variably related to effort. Three years previously she had had a carcinoma of the cervix removed and since then her chief symptoms had been breathlessness and chest pain on effort. During the two months before admission she had had two fainting attacks, both of which had occurred without warning, and the chest pain had occasionally come on whilst she was at rest.

She was an obese normotensive woman in gross congestive cardiac failure, whose chest film showed an ill-defined mass at the left hilum. Sudden death occurred three days after admission.

Necropsy revealed no recurrence of the cervical cancer. In the apex of the left lower lobe was a soft white mass of grapefruit size, which showed no evidence of central necrosis and which was clearly metastatic in origin. General visceral congestion was present elsewhere. The heart was enlarged and flabby, the coronary arteries being normal in appearance and distribution. No evidence of infarction was detected, and there were no valvular or septal defects. The left atrial cavity was occupied by a mass of grey neoplastic tissue which was attached to the posterior wall by a short pedicle some $2 \mathrm{~mm}$. in diameter. At the base of the pedicle invasion of the atrial wall extended for only a few millimetres in any direction: the mass showed no sign of necrosis and there was no antemortem thrombus attached to it. The functional vascular pathway must necessarily have been severely limited. Both tumour masses consisted of undifferentiated carcinoma.

\section{CASE 4}

A 46-year-old woman had previously been treated surgically at this hospital for carcinoma of the breast. After radiotherapy she remained well for three years until the development of a pathological fracture in the femur. In hospital she developed atrial flutter: when cardiac failure developed diuretics and quinidine were added to the digitalis but she died suddenly with unrelieved flutter.

At necropsy there was a well healed mastectomy scar with radiation telangiectases but no sign of local recurrence. Numerous soft deposits of growth were present throughout both lungs and in the ribs and vertebrae. The right heart was dilated, and in the atrial wall just above the tricuspid valve near the entrance of the coronary sinus was a pea-sized white nodule, with a recent area of haemorrhage within it. 


\section{CASE 5}

A 54-year-old man was admitted with severe dyspnoea, cyanosis, and congestive heart failure. $\mathrm{He}$ died before an accurate history could be obtained, but it was subsequently found that he had suffered with his chest for many years though he had not sought medical advice.

Necropsy revealed a large ulcerating bronchogenic carcinoma, arising from the left main bronchus, which had invaded the mediastinum and infiltrated the pericardium. This was 0.5 to $1.5 \mathrm{~cm}$. in thickness, rock hard, and closely applied to the heart, which in places showed malignant invasion of the myocardium. Evidence of long-standing bronchiectasis was also present.

\section{DISCUSSION}

Pulmonary metastatic malignant disease is common and mostly arises as a result of lymphatic or bloodstream spread. Diffuse lymphatic carcinomatous infiltration which produces secondary vascular thrombosis (Brill and Robertson, 1937) was reviewed by Harold (1952), but only one of this author's personal series of 24 cases showed terminal cardiac failure, and such a termination is rarely recorded (Greenspan, 1934 ; Krygier and Brill, 1942). Whilst lymphatic permeation has been noted frequently at necropsy since the time of Troisier (1873), it is only recently that the resulting disturbed physiology has become recognized as a cause of the clinical syndrome of alveolar-capillary block (Arnott, 1955). Many patients do not survive to reach this stage but post-mortem search often reveals widespread microscopic involvement (Harold, 1952; Willis, 1960). Repeated vascular emboli of clumps of malignant cells either by immediate blockage or the initiation of local thrombosis lead to obstructive pulmonary hypertension which can be diagnosed clinically (Mason, 1940).

The microscopic demonstration of fibrous tissue around the malignant emboli suggests a defensive (or offensive) reaction by the patient. This fibrous tissue may be responsible for the obliteration of the pulmonary vascular bed and also for the extensive interstitial pulmonary fibrosis sometimes seen in metastatic disease of the lungs. The role of the stromal reaction in neoplasia may thus be more important than the actual presence of tumour itself, for patients with extensive lung metastases are seen (e.g., case 4) in whom there is no evident fibrotic reaction and no clinical sign of cardiac failure. The presence of secondary deposits in the lung fields is generally taken to indicate a poor prognosis, but individual variation is very great.
Prolonged survival in malignant disease is weगु recognized (Cameron, 1909; Sutton, 1961), ang a state of partial immunity has been suggested te exist in such patients (Boyd, 1921): the fibrou reaction may be tangible evidence of this.

Cardiac metastasis was first recorded almost century ago (Bodenheimer, 1865), and tumoū emboli recognizable in the cardiac capillaries have been reported (Foot, Carter, and Flipse, 1924\$ Raven (1948) states that secondary cardia deposits arise from coronary artery distributio by retrograde lymphatic spread from the tracheos bronchial nodes, by lymphatic spread (thoracid duct to right heart) or by direct invasion (as if case 5). Left-sided endocardial implantation $\vec{t}$ very rare (Hunter, 1922) and although it seem? reasonable to assume that the deposit in case $\overrightarrow{4}$ was the result of coronary artery embolism, seems most likely that the peculiar deposit is case 3 was seeded on to the left atrial wall from the deposit in the apex of the left lower lobes Secondary embolism from intracardiac metastasis has been reported from time to time (e.g. Thompson and Evans, 1930). Invasion of thes myocardium, as in case 5 , is not uncommo (Willis, 1960), and three similar cases have bee⿳⺈⿴囗十 encountered since. There is usually massive involvement of the mediastinum, and in additio $\vec{B}$ to the limitation of expansion there may be $a$ i element of compression present. Sudden deteriora tion in these patients is due to pulmonary infeco. tion, cardiac failure or pulmonary arter thrombosis.

When the primary growth can be influenced bơ hormone therapy there is some hope that cardias failure due to cancer may be alleviated even if the metastases are less responsive than the primary lesion. When much fibrosis is responsible little improvement can be expected of eithe? hormone or steroid therapy. Infection should bo treated energetically and accepted measures. applied for the relief of heart failure. In selected cases slow transfusion of packed red cells may be considered justifiable, and if the anaemia, which may be leuko-erythroblastic (Jarcho, 1936), caß̈ be thus controlled, cytotoxic therapy may b区 attempted. The special danger of this is severe pulmonary haemorrhage.

\section{SUMMARY}

Five cases of cardiac failure due to malignan $\frac{\mathbb{1}}{\stackrel{1}{2}}$ disease are reported. The pathogenesis an management are briefly discussed. 
I am indebted to Dr. D. G. B. Richards for permission to publish details of these cases and for advice and criticism during the preparation of this paper.

\section{REFERENCES}

Anderson, W. A. D. (1961). Pathology, 4th ed. Mosby, St. Louis. Arnott, W. M. (1955). Order and disorder in pulmonary function. Brit. med. J., 2, 279.

Bodenheimer (1865). Cited by Willis.

Boyd, W. (1921). Tissue resistance in malignant disease. Surg. Gynec. Obstet., 32, 306.

Brill, I. C., and Robertson, T. D. (1937). Subacute cor pulmonale. Arch. intern. Med., 60, 1043.

Cameron, H. C. (1909). Some clinical facts regarding mammary cancer. Brit. med. J., $1,577$.

Foot, N. C., Carter, B. N., and Flipse, M. J. (1924). An unusual malignant tumour of the pancreas. Amer. J. med. Sci., 167, 76.

Greenspan, E. B. (1934). Carcinomatous endarteritis of the pulmonary vessels resulting in failure of the right ventricle. Arch. intern. Med., 54, 625.
Harold, J. T. (1952). Lymphangitis carcinomatosa of the lungs. Quart. J. Med., n.s. $21,353$.

Hunter J. B. (1922) Case of general vascular carcinoma. Proc. roy. Soc. Med., 15, Sect. Obstet., p. 22.

Jarcho, S. (1936). Diffusely infiltrative carcinoma. Arch. Path., 22, 674. Krygier, J. J., and Brill, I. C. (1942). Subacute cor pulmonale due to metastatic carcinomatous lymphangitis of the lungs. Northw. Med. (Seattle) 41, 319.

Mason, D. G. (1940). Subacute cor pulmonale. Arch. intern. Med., 66,

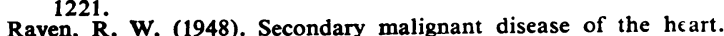
Brit.J. Cancer, 2, 1.

Sutton, M. (1961). Prolonged survival with pulmonary metastases. Brit. med. J., 1, 290.

Thompson, T., and Évans, W. (1930). Paradoxical embolism. Quart. $J$.Med. 23,135 .

Troisier, E (1873). Cancer de l'estomac; cancer secondaire des poumons. Lymphangite pulmonaire généralisée. Bull. Soc. poumons. Lymphan

Willis, R. A. (1960). Pathology of Tumours. 3rd ed. Butterworths,

London.
Wood, P. (1956). Diseases of the Heart and Circulation. Eyre and Spottiswoode, London. 